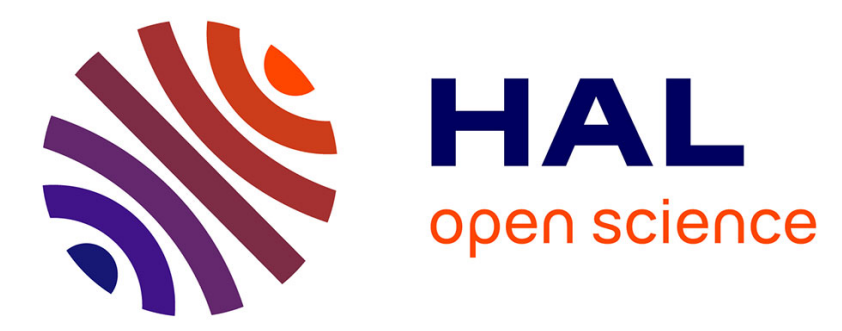

\title{
Diamond Deposition Using a Grid Filament
}

D. Li, T. Mäntylä, J. Levoska

\section{To cite this version:}

D. Li, T. Mäntylä, J. Levoska. Diamond Deposition Using a Grid Filament. Journal de Physique IV Proceedings, 1995, 05 (C5), pp.C5-989-C5-995. 10.1051/jphyscol:19955116 . jpa-00253786

\section{HAL Id: jpa-00253786 https://hal.science/jpa-00253786}

Submitted on 1 Jan 1995

HAL is a multi-disciplinary open access archive for the deposit and dissemination of scientific research documents, whether they are published or not. The documents may come from teaching and research institutions in France or abroad, or from public or private research centers.
L'archive ouverte pluridisciplinaire HAL, est destinée au dépôt et à la diffusion de documents scientifiques de niveau recherche, publiés ou non, émanant des établissements d'enseignement et de recherche français ou étrangers, des laboratoires publics ou privés. 


\title{
Diamond Deposition Using a Grid Filament
}

\author{
D.M. Li, T. Mäntylä and J. Levoska*
}

Institute of Materials Science, Tampere University of Technology, P.O. Box 589, 33101 Tampere, Finland * Microelectronics and Material Physics Laboratories, University of Oulu, P.O. Box 400, 90571 Oulu, Finland

\begin{abstract}
A grid tantalum filament of a dimension of $3 \times 4 \mathrm{~cm}^{2}$ was used for diamond synthesis by hotfilament assisted chemical vapour deposition (HFCVD). After proper carburization, the filament could be used for multi-cycles of deposition. By heating the filament to $2400^{\circ} \mathrm{C}$ in $8 \% \mathrm{CH}_{4}$ mixed with $\mathrm{H}_{2}$, diamond has been deposited at rate of about $5 \mu \mathrm{m}$ /hour on (100) oriented silicon substrate placed $5 \mathrm{~mm}$ away from the filament. By X-ray diffraction (XRD), the structure of the films deposited in the mixture of $\mathrm{CH}_{4}$ and $\mathrm{H}_{2}$ was characterized as diamond, while tantalum oxide was found in the presence of oxygen during deposition. The deposited diamond appeared uniform over an area of $2 \times 3 \mathrm{~cm}^{2}$ observed by scanning electron microscopy (SEM) perhaps due to the stable filament geometry. Raman spectra of these films showed a sharp peak near $1332 \mathrm{~cm}^{-1}$, which indicated the presence of a large amount of $s p^{3}$ bonds in the film. The present grid filament can be scaled-up for large area diamond deposition.
\end{abstract}

\section{INTRODUCTION}

Hot filament assisted chemical vapour deposition (HFCVD) is one of the effective techniques to deposit diamond in metastable conditions. Generally, the deposition rates of diamond by this technique are lower than $2 \mu \mathrm{m} / \mathrm{h}$ at filament temperatures below $2300^{\circ} \mathrm{C}$. Recently, the deposition rate has been improved by using higher filament temperatures and higher methane concentrations [1-3]. For large area diamond deposition, a bigger filament is needed. In HFCVD it is common to shape the filament into the geometry of a coil. Farabaugh et al. [4] used dual coiled filaments which were made of tungsten wire to enlarge the deposition area. Diamond was deposited at the rates of lower than $0.4 \mu \mathrm{m} / \mathrm{h}$ and the uniformity of the deposition was not reported. A few tests have also been carried out using grid filaments to deposit diamond films on large areas. Rhenium filament can be used for long period time, at temperatures around $2000^{\circ} \mathrm{C}$, but the diamond deposition rates are very low [5]. Joeris et al.[6] claimed that their tungsten grid filament could be used in many cycles of operation. However, diamond deposition rate was not reported. Schäfer et al.[7] used vertically arranged tantalum wires as their filament. They found that diamond deposition rates were lower than $0.5 \mu \mathrm{m} / \mathrm{h}$ and the rate varied considerably at different substrate positions. 
The present study intends to use a carburized tantalum grid filament to deposit diamond on a large area with an improved deposition rate by using filament temperatures higher than the grid filaments mentioned above.

\section{EXPERIMENT}

The HFCVD apparatus used in this study consists of a cylindrical stainless steel chamber, a power supply and a gas feeding system. The essential component of the apparatus is the filament arrangement which is schematically shown in Fig. 1. The grid filament having dimensions of $3 \times 4 \mathrm{~cm}^{2}$ consists of several tantalum wires in parallel. On a water cooled substrate holder, a silicon substrate with dimensions of $2 \times 3$ $\mathrm{cm}^{2}$ is placed $5 \mathrm{~mm}$ below the filament. The substrates were polished with $1 \mu \mathrm{m}$ diamond spray prior to deposition. In this process, the filament temperature was measured by a two wave-length optical pyrometer which had been calibrated with a black-body radiator. The substrate was heated by the filament radiation and the substrate temperature was measured by a thermo couple mounted beside the substrate. The water cooled substrate holder can be adjusted to regulate the distance from the substrate to the filament.

Typical deposition time was 1 hour. To avoid the substrate overheating, it was lowered to about $10 \mathrm{~mm}$ away from the filament after 1 hour deposition in order to let the substrate cool down. After a 10 min cooling period the substrate was erected to the position where the deposition continued. The filament was carburized in $6 \% \mathrm{CH}_{4}+94 \% \mathrm{H}_{2}$ at temperatures of $2000 \sim 2400^{\circ} \mathrm{C}$. Deposition parameters are listed in Table 1. The deposited films were characterized by X-ray diffraction (XRD, D500, Siemens), scanning electron microscopy (SEM 515, Philips) and hot filament

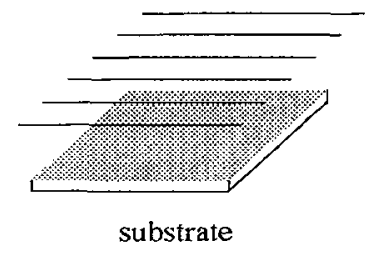

Fig. 1. The arrangement of grid filament Raman spectroscopy (Jobin-Yvon T64000).

Table 1. Deposition parameters

\begin{tabular}{ll}
\hline Filament temperature $\left(\mathrm{T}_{\mathrm{p}}\right)$ & $2400^{\circ} \mathrm{C}$ \\
Substrate Temperature $\left(\mathrm{T}_{s}\right)$ & $950-1050^{\circ} \mathrm{C}$ \\
Total gas pressure $(\mathrm{P})$ & $4 \mathrm{kPa}$ \\
Total gas flow rate & $100 \mathrm{sccm}$ \\
$\mathrm{CH}_{4}$ concentration & $6-8 \%$ \\
$\mathrm{O}_{2}$ concentration & $0,2 \%$ \\
Filament to substrate distance $(d)$ & $5 \mathrm{~mm}$ \\
deposition time & $1 \mathrm{~h}, 2 \mathrm{~h}$ \\
\hline
\end{tabular}




\section{RESULTS}

After 2.5 hours of heating, a newly installed filament was fully carburized into TaC as characterized by XRD (Fig. 2). Such carburized filament can be repeatedly used for diamond deposition. Films deposited in 1 hour showed well defined crystalline features (Fig. 3). The crystal structure of the films were identified by XRD to be pure polycrystalline diamond (Fig. 4). The sharp peak in $1332 \mathrm{~cm}^{-1}$ of the Raman spectra of these films (Fig. $5 \mathrm{a} \sim \mathrm{c}$ ) indicated that the films were essentially $s p^{3}$ bonded. The broad band in the spectra near $1550 \mathrm{~cm}^{-1}$ represented the presence of amorphous carbon in the films, but the bonding in the film is $s p^{3}$ dominated.

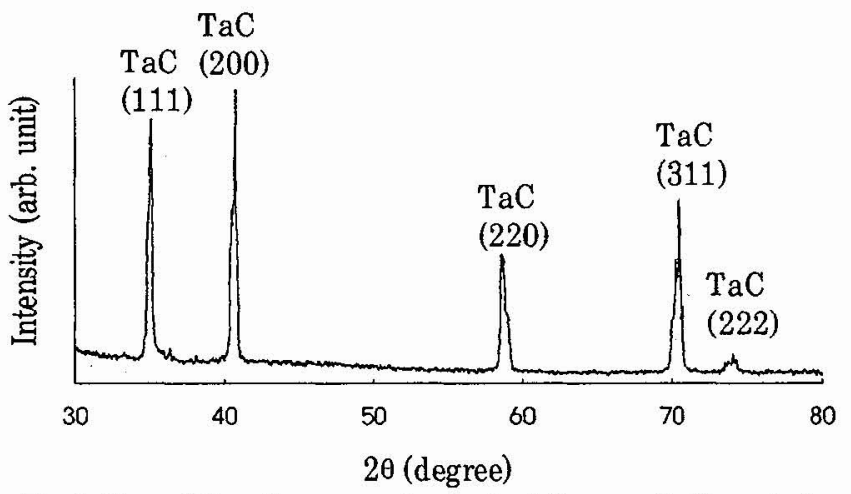

Fig. 2. X-ray diffraction pattem of carburized filament, $\mathrm{Cu}$ K $\alpha$ radiation

It was found difficult to control the substrate temperature during the deposition. The substrate temperature increased gradually as deposition proceeded although the flow of cooling water was continuously increased. As the deposition exceeded 1 hour the film began to become dark in the middle and this dark area expanded due to the substrate overheating. The grains of this dark area became hemispheres as observed by SEM (Fig. 6). No diamond was found in this area by Raman spectrum, and the centre of the broad band was shifted to the range of 1580 and $1600 \mathrm{~cm}^{-1}$ (Fig. 5d) which indicates the formation of graphite [8]. The
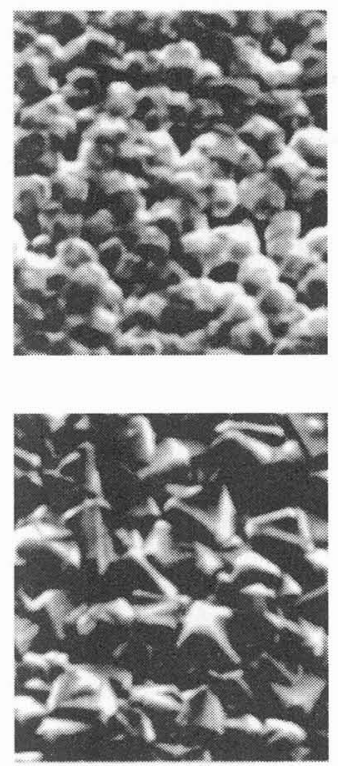

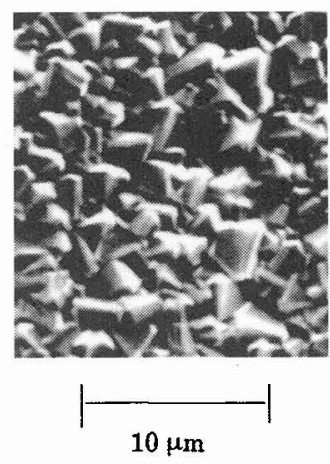

Fig. 3. Morphology of diamond films obtained with different methane concentrations
a. $6 \% \mathrm{CH}_{4}$
b. $7 \% \mathrm{CH}_{4}$
c. $8 \% \mathrm{CH}_{4}$
1 hour 


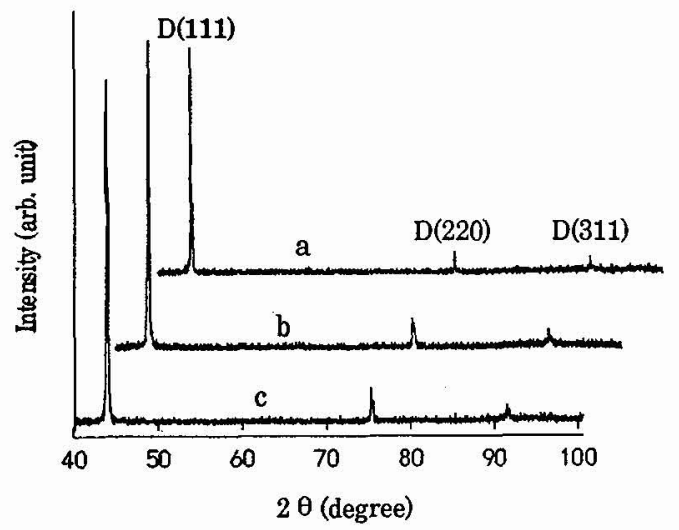

Fig. 4. X-ray diffraction pattern of diamond films, $\mathrm{Cu}$ K $\alpha$ radiation. $\mathrm{a}, \mathrm{b}, \mathrm{c}$ refer to the corresponding morphologies in Fig. 3.

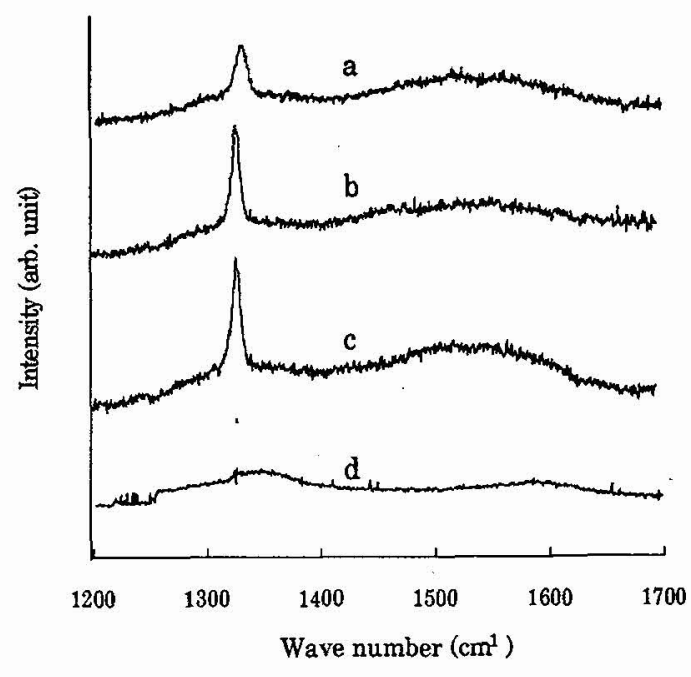

Fig. 5. Raman spectra of diamond films, a, b, c refer to the corresponding morphologies in Fig. 3. $d$ to the film shown in Fig. 6.

filament showed brown color when $2 \% . \mathrm{O}_{2}$ was used. It was found by XRD that the filament was oxidiz

In two hours deposition with $10 \mathrm{~min}$ cooling interval, the substrate was not observed to be overheated. The film morphology was uniform throughout the substrate area as shown in Fig. 7. The Raman spectra of such deposited film also showed a good uniformity of the diamond film (Fig. 8). The deposition rate of diamond film was about $5 \mu \mathrm{m} / \mathrm{h}$ with $8 \% \mathrm{CH}_{4}$ concentration. The film thickness of the centre region of the film is slightly thinner than that of the edge region with the maximum difference of about $10 \%$.

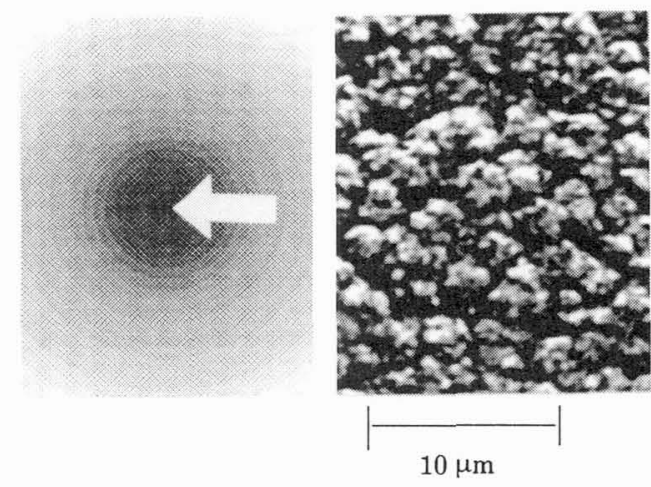

Fig. 6. Schematic illustration (a) of overheated substrate area and the morphology of the film in this area 


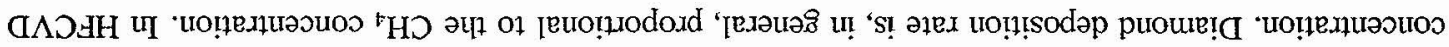

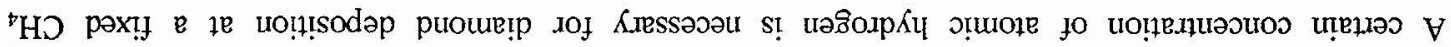

NOISSnDSIA

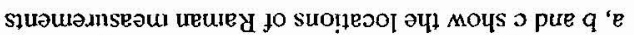

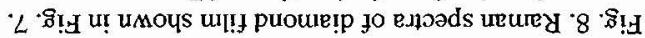

(4- us) dəqunu $ә \Lambda \mathcal{E}_{M}$

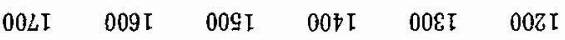

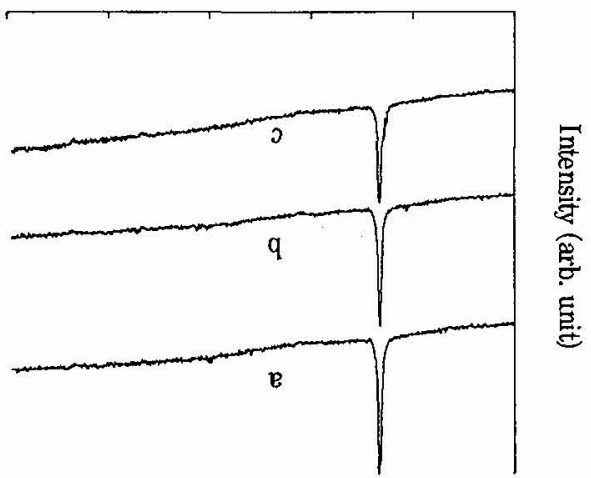

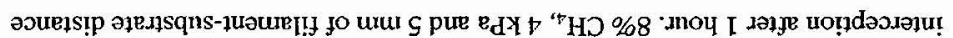

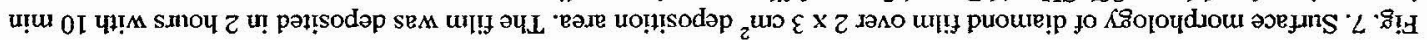
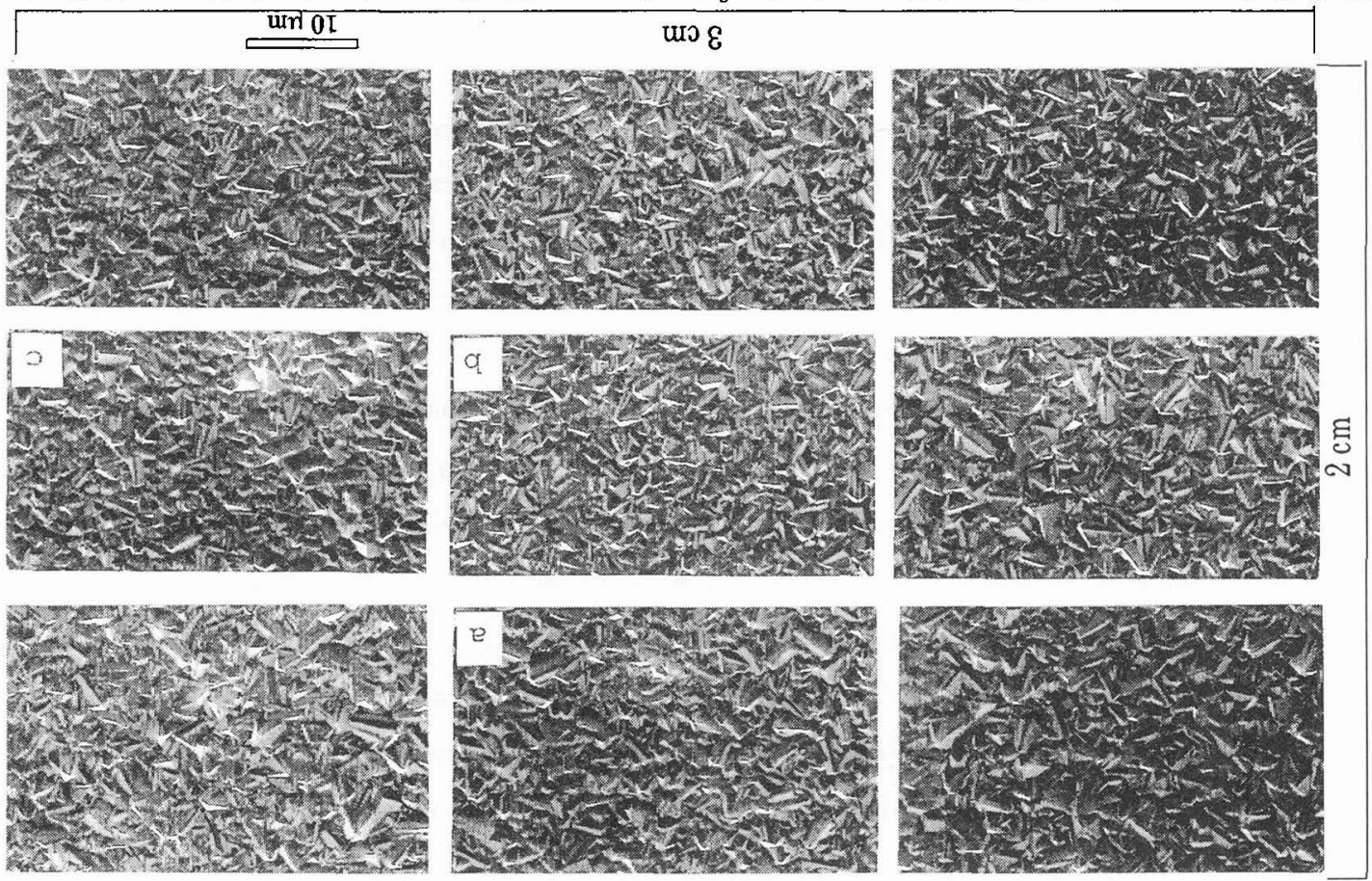
the concentration of atomic hydrogen is increased when the filament temperature increased [9]. In the case of coil filament, it has been proved that $\mathrm{CH}_{4}$ concentration can be increased when the filament temperature is increased [1 3]. Our present study proved that, with the grid filament, high $\mathrm{CH}_{4}$ concentrations up to $8 \%$ can be applied to deposit pure diamond film at $\mathrm{T}_{\mathrm{f}}$ of $2400^{\circ} \mathrm{C}$.

The overheating of the substrate is the main problem with grid filament. This limits both $\mathrm{T}_{\mathrm{f}}$ and deposition time and consequently the deposition rate. In our early studies [2 $\sim 3]$ much higher filament temperatures, $2600^{\circ} \mathrm{C}$ to $2890^{\circ} \mathrm{C}$, could be used for high quality diamond deposition. In the present study even at $\mathrm{T}_{\mathrm{f}}$ of $2400^{\circ} \mathrm{C}$ the radiation from the filament resulted after 1 hour in overheating of the center part of the substrate. This could not be avoided by enhanced substrate cooling. The intercepted deposition, allowing the cooling after 1 hour deposition, was an effective way to avoid the local substrate overheating and made it possible to grow thicker diamond films.

In the present study, $T_{f}$ was measured as an average value of the filament temperature. The actual temperature in the middle of the filament may be higher than that of filament edge due to temperature gradient from the filament to the chamber wall which means it is difficult to determine the temperature distribution of the filament. Further studies are needed to measure the real temperature distribution of the filament and the substrate. This information is needed to improve the temperature uniformity and to optimize the geometry design of the filament. This can result in grid filaments which make possible the deposition of uniform diamond structure over extended substrate areas with reasonable deposition rate.

\section{CONCLUSIONS}

Using a grid TaC filament diamond films could be deposited on silicon substrate over an area of $2 \times 3 \mathrm{~cm}^{2}$. At $\mathrm{T}_{\mathrm{f}}$ of $2400^{\circ} \mathrm{C}$ and $8 \% \mathrm{CH}_{4}$ diamond films have been deposited with a rate of about $5 \mu \mathrm{m} / \mathrm{h}$. The substrate was overheated by the filament when deposition exceeded 1 hour. Such overheating can be avoided by an interrupted deposition. By careful optimization of the geometry of the grid filament and the heat balance of the system, it is possible to deposit diamond films even on larger substrate areas with reasonable rate.

\section{Acknowledgments}

The Authors are grateful to Dr. R. Hernberg and his group from the Laboratory of Plasma Technology, Tampere University of Technology for their helpful discussion and providing the facility for filament temperature measurement. The financial support of this study by the Centre for International Mobility of Finland is greatly acknowledged. 


\section{References}

[1] H. Matsubara and T. Sakuma, J. Mater. Sci. 25 (1990) 4472-4476

[2] J. Brückner and T. Mäntylä, Diamond and Related Materials 2 (1993) 373-377

[3] D. M. Li, T. Mäntylä and J. Levoska, J. de Physique IV3 (1993) 597

[4] E. N. Farabaugh, A. Feldman and L. H. Robins, "Effects of multiple filament geometry in the hot filament deposition of diamond films", Proceedings of the First International Conference on the Applications of Diamond Films and Related Materials, Alabama, USA, August 17-22, 1991, Y. Tzeng, M. Yoshikawa, M Murakawa and A. Feldman Eds. (Elsevier, Amsterdam - Oxford - New York - Tokyo 1991) pp 483-488

[5] F. Jansen, M. A. Machonkin and D. E. Kuhman, J. Vac. Sci. Teclinol. A8 (1990) 3785-3790

[6] P. Joeris, C. Benndorf and S. Bohr, "Diamond Deposition by Hot Filament and Microwave CVD: Influence of Deposition Parameters on Phase Purity, Surface Roughness and Film Quality", Proceedings of the First International Conference on the Applications of Diamond Films and Related Materials, Alabama, USA, August 17-22, 1991, Y. Tzeng, M. Yoshikawa, M Murakawa and A. Feldman Eds. (Elsevier, Amsterdam - Oxford - New York - Tokyo 1991) pp 561-566

[7] L. Schäfer, M. Sattler and C.-P. Klages, "Upscaling of the Hot-Filament CVD Process for Deposition of Diamond Films on Large-Area Substrates", Proceedings of the First International Conference on the Applications of Diamond Films and Related Materials, Alabama, USA, August 17-22, 1991, Y. Tzeng, M. Yoshikawa, M Murakawa and A. Feldman Eds. (Elsevier, Amsterdam - Oxford - New York - Tokyo 1991) pp 453-460

[8] D. S. Knight and W. B. White, J. Mater. Res. 4 (1989) 385-393

[9] F. G. Celii and J. E. Butler, Appl. Phys. Lett. 54 (1989) 1031-1033 
